\title{
Futebol em Salvador: o início de uma história (1899-1920)
}

\author{
Coriolano Pereira Rocha Junior* \\ Fernando Reis do Espírito Santo**
}

\begin{abstract}
RESUMO: Este estudo aborda o futebol em Salvador e objetiva identificar formas e sentidos de sua chegada na cidade e analisar sua trajetória e construção como prática social, entre 1899 e 1920. Justifica-se este texto pela importância de Salvador na política e na economia do país, já que foi uma das primeiras cidades a ter o futebol. O futebol iniciou-se na elite, como uma prática de valores "modernos" até ganhar popularidade, alcançando toda cidade, da mesma forma se constituíram os clubes, de elite no início, depois populares ou de colônias de estrangeiros. A prática se iniciou em praças, até se construir um campo próprio, sua trajetória seguiu o processo de tentar incluir a cidade na modernidade.
\end{abstract}

Palavras-chave: Futebol. História. Salvador-BA; Modernidade.

\section{INTRODUÇÃo}

O futebol é reconhecidamente uma das práticas sociais de maior relevância no Brasil e no mundo, sendo um dos ou mesmo o principal fenômeno social da atualidade, por ser capaz de mobilizar grande massa de pessoas interessadas em sua prática. Foer (2005, p.9) afirma que o futebol é algo que "frequentemente provoca um sentimento mais profundo que a religião e, tal como esta, é uma parte do tecido comunitário, um repositório de tradições".

Para Salvador (2005, p.5), no Brasil, esse esporte, acaba agindo como uma instituição social, reforçando "os elos de pertencimento, afirmando nossas virtudes e valores, expressos no corpo de nossos

\footnotetext{
*Faculdade de Educação de Salvador, BA, Brasil. E-mail: coriolanojunior@uol.com.br.

**Faculdade de Educação da Universidade Federal da Bahia (UFBA). Salvador, BA, Brasil. Email: fres.nando@uol.com.br
} 
jogadores". Para Byington (1982, p.21), o futebol só "faz vibrar a alma individual e cultural de um povo na medida em que contém os símbolos que expressam e nutrem a vida psíquica deste povo".

Pereira (2000) afirma que "apesar do sucesso alcançado pelo esporte, essa é uma questão que só recentemente começa a merecer por parte de pesquisadores e estudiosos maiores atenções" (p.15). Por conta desta magnitude do futebol como um fenômeno social, podemos pensar na constituição de um campo de estudos ao seu redor, sendo a história um dos meios para estudá-lo e foi sob a perspectiva histórica que esse artigo se construiu.

O problema que pautou esse estudo foi esse: como seu deu a construção do futebol em Salvador e como se deram as adesões e resistências a sua prática? A hipótese deste texto é a de que em Salvador, o futebol, percorreu trajetória semelhante a outras cidades brasileiras, sendo inicialmente uma prática da elite ${ }^{1}$, para depois, se entranhar na cidade como um todo, modificando-se as formas de apropriação e prática do esporte.

Como objetivo, este estudo procurou identificar a entrada do futebol em Salvador e ainda, analisar como se deu sua construção como prática esportiva relevante, tentando entender a trajetória da experiência futebolística na cidade, entre 1899 e 1920 . A escolha do período se deu, por identificarmos, que em 1899, foram fundados os primeiros clubes esportivos ${ }^{2}$, que adiante passaram a praticar o futebol, e que em 1920, o esporte já vivia uma fase de consolidação (LEITE; ROCHA JUNIOR; SANTOS, 2010).

A metodologia utilizada foi à pesquisa histórica, na linha da nova história cultural, por essa trabalhar com objetos que não eram percebidos como centrais, caso do esporte. Burke (2005, p. 78) afirma que "graças a essa virada em direção as práticas, a história do esporte, que antes era tema de amadores, tornou-se profissionalizada, um

\footnotetext{
'Parcela da população que detinha poder político-econômico, com acesso a formação escolar e cultural, no Brasil ou fora dele.

${ }^{2}$ Club de Cricket Victoria (maio) e Club Internacional de Crick (novembro).
} 
campo com suas próprias revistas...". Essa "virada" aconteceu quando a história dialogou com outras áreas, dando sentido a novas práticas como objetos de pesquisas, caso do esporte. Assim, nas últimas décadas, estudos sobre história do esporte têm avançado como uma nova área de investigação, a partir da ação de "... pesquisadores que, independente de sua filiação acadêmica original, procuram fazer uso das discussões metodológicas do campo da história (MELO, 2007b, p.14)". Neste texto, as fontes utilizadas foram: periódicos locais de circulação em Salvador (jornais e revistas), mais a literatura específica nacional e memorialistas baianos.

Mais do que identificar responsáveis pela chegada do futebol no Brasil e em Salvador, interessa-nos compreender como ele passou a circular no cotidiano. Nesse mesmo sentido, Franco Junior (2007, p. 62). aponta que:

[...] estabelecer paternidades quase heróicas e datas oficiais não esclarece as relações entre o futebol e a sociedade brasileira. Pelo contrário, suas significações mais profundas residem no processo de apropriação pelos diversos setores sociais que o transformaram num fenômeno de massas .

Dessa forma, entendemos ser possível compreender os primórdios do futebol em Salvador, passando antes por um olhar sobre o Brasil. Assim, essa produção se associa a uma linha de estudos que tratam o futebol como um fenômeno social, buscando compreende-lo sob o viés da história. Sobre Salvador, ainda são escassos estudos nessa linha, o que faz com que essa produção atue na ampliação desse tema de pesquisas na Bahia.

\section{FUTEBOL NA SOCIEDADE E NA CULTURA BRASILEIRA}

Sobre o futebol no Brasil, se fala que Charlles Miller e Oscar $\mathrm{Cox}^{3}$ foram os responsáveis por sua introdução no país. Sem negar a importância desses homens na sistematização do futebol, já se

\footnotetext{
${ }^{3}$ Apontados respectivamente como sendo responsáveis pela organização do futebol em São Paulo e no Rio de Janeiro.
}

Movimento, Porto Alegre, v. 17, n. 03, p. 79-95, jul/set de 2011. 
sabe que esse esporte, antes desse processo inicial de organização, existia no país como uma prática escolar. Melo (2000, p. 19) afirma que

No Brasil, desde os tempos da Colônia, existiam colégios jesuítas ${ }^{4}$, e foi provavelmente através deles que chegaram as primeiras bolas de futebol e se realizaram os primeiros jogos. Como dissemos, ainda não havia clubes, campeonatos e entidades, mas o esporte praticado já era o futebol moderno segundo o modelo inglês.

Mesmo tendo no Brasil suas origens nos braços da elite, o futebol não demorou a atrair o interesse da população, se tornando uma das práticas mais populares. Sobre isto, Melo (2007a, p. 74) assevera que:

[...] enquanto outros esportes exigiam espaços e equipamentos custosos, para a prática do futebol bastava um terreno vazio, traves e bolas improvisadas. A prática, aliás, era bem adequada ao gosto popular, com sua necessidade de coletividade, com suas possibilidades de improvisação, bem como por certa permissividade simbólica de uma violência controlada, próxima a algumas manifestações populares...

Esse movimento não se deu de forma simples e direta e tampouco teve fácil "digestão" pelas elites, permitindo-nos perceber uma característica da entrada do futebol no Brasil e em Salvador, a ambiguidade.

Iniciado no Brasil como uma atividade "civilizada", uma das representações dos modos e práticas da elite, o futebol, em seu caminhar, foi também uma atividade combatida, um esporte "incivilizado", notadamente quando jogado por populares ${ }^{5}$. Se em seu princípio o futebol foi um modo de "educar" e de civilizar ${ }^{6}$ o povo

${ }^{4} \mathrm{O}$ mesmo autor aponta que os colégios Colégio São Luiz (Itu-SP) e Anchieta (Nova Friburgo$\mathrm{RJ})$, foram os primeiros.

${ }^{5}$ Parcela da população de mais baixa renda ou sem renda e que esteve fora dos processos formais de introdução do futebol no país.

${ }^{6}$ Entendido como a incorporação de um conjunto de representações e de ações relativas à convivência social, sob moldes europeus.

Movimento, Porto Alegre, v. 17, n. 03, p. 79-95, jul/set de 2011. 
a partir de uma "bela" prática, na tentativa de incorporar toda uma ritualidade comportamental europeia, foi adiante apropriado e ressignificado pelas camadas populares, passando a ser um dos seus interesses culturais e praticado de formas mais espontâneas, diferentes do esporte formalizado, inclusive no que toca aos equipamentos e espaços ${ }^{7}$ de jogo.

Pode-se dizer que o

[... ] futebol foi introduzido no Brasil sob o signo iniludível do novo, pois, muito mais do que um simples "jogo", ele constava da lista de coisas civilizadas e moderníssimas a serem adotadas pela sociedade brasileira, uma sociedade vista por suas elites como atrasada e, com a Proclamação da República, em alvoroço para recuperar o tempo perdido. Além disso, esse jogo de bola era algo relativamente desconhecido, mas que chegava do maior império colonial do mundo, da prestigiosa Inglaterra - no bojo de uma novidade chamada "esporte" (DaMATTA, 2006, p. 136).

O futebol, como uma prática social, é apontado como um dos elementos que vão contribuir para a formação das identidades locais e nacionais. Entendemos que as identidades são representações culturais $^{8}$, portanto, mutáveis e assim, são sempre transformadas em função de cada contexto (HALL, 2005). Por isso, o futebol é um meio efetivo de caracterização e representação dessas identidades, justo por ser um espaço onde se demonstram os arranjos e expressões culturais que caracterizam modos diversos de se jogar e de se ver o jogo (GUEDES, 2009). Assim, DaMatta (1982, p. 22), ao entender que o futebol pode significar uma representação da cultura nacional, apresenta a afirmação de que "o futebol praticado, vivido, discutido e teorizado no Brasil seria um modo específico, entre tantos outros,

\footnotetext{
${ }^{7}$ São os locais da cidade escolhidos para o futebol. Relacionam-se as adaptações as exigências formais do esporte e suas apropriações culturais pela população, inclusive no que se refere a adaptação dos materiais de jogo.

${ }^{8}$ Cultura é vista aqui como uma produção humana, um arranjo de normas, hábitos, valores e expressões, construídas sob tensões de várias dimensões.
} 
pelo qual a sociedade brasileira fala, apresenta-se, revela-se, deixando-se, portanto, descobrir".

Nesse sentido, Giulianotti (2002, p. 42) afirma que:

o futebol é uma das grandes instituições culturais, como a educação e os meios de comunicação de massa, que formam e consolidam identidades nacionais no mundo inteiro. A difusão internacional do futebol durante o final do século XIX e o início do século XX ocorreu quando a maior parte das nações na Europa e na América Latina estava negociando suas fronteiras e reformulando suas identidades culturais.

Com isso, vemos que o futebol, no Brasil, saiu da alçada única da elite e adentrou o cotidiano popular, ganhando projeção como uma prática cultural. Interessa-nos agora compreender como Salvador fez parte desse jogo.

\section{O futebol Soteropoltano}

Sobre Salvador, alguns autores mostram que a chegada do futebol se deu pelas mãos de brasileiros que tinham passado pela Inglaterra e por lá o experimentado e que então, tentaram trazer para seu local de origem, as mesmas práticas vividas na Europa e para tanto, precisavam dinamizar essa experiência na cidade.

Leal (2002, p. 180) fala o seguinte:

$\mathrm{Na}$ Bahia, os rapazes desejavam praticar aquela modalidade de esportes, quando chegou à cidade do Salvador, o estudante José Ferreira, de alcunha Zuza, que tinha concluído seu curso na Inglaterra e viria para empregar-se no Bank of London, nesta capital. Sabia ele que em Salvador os esportes existentes eram o cricket, no Campo Grande, praticado pelos ingleses e as corridas de cavalo no Ground do Rio Vermelho e da Boa Viagem.

Nesse início, ao mesmo tempo em que havia uma aceitação do futebol, eram também vistas notícias que dele falavam mal, quando 
sua prática se dava entre populares. Sobre essa resistência ao futebol em Salvador, Leal (2002, p. 181), analisando jornais de época, demonstra que

Quantas vezes a cavalaria perseguiu empinadores de arraias, acabou babas ${ }^{9}$ em todos os locais, em todas as ruas e em todos os tempos. Como uma confirmação, que seriam muitas se fôssemos anotar. O Diário de Notícias, em 11 de junho de 1907, fazia uma denúncia contra " o foot-ball (futebol) de garotos no Largo de São Bento, que reúnem-se todos os dias naquele largo. É uma turma de desocupados jogando foot-ball, quebrando vidraças, vidros de lampiões públicos, incomodando o transito..." ${ }^{10}$..

Pode-se ver que o futebol, quando enquadrado nas normas de civilidade e disciplinarização, era aceito e benquisto, por expressar os sentidos e aspirações da elite de Salvador, que se inspirava em modelos europeus sobre como se portar e vivenciar seu dia a dia. Todavia, esse mesmo futebol, sofria resistências quando aparecia de forma "desordenada" na cidade, sem atentar para os princípios da modernidade/civilidade, dentre eles, a regulação de comportamentos, sendo uma prática a ser combatida e isso acontecia quando essa se dava entre populares.

Segundo Franco Júnior (2007, p.62), a organização dos clubes de futebol no Brasil seguiu duas tendências. A primeira consistia justamente na "[...] formação de equipes no interior dos grupos dominantes, orientada pelos valores do cavalheirismo, do fairplay e do amadorismo". Já a segunda tendência, é justamente aquela "onde as fronteiras sociais do futebol começaram a ser transpostas desde cedo com a formação de times improvisados pelos setores populares..." (FRANCO JÚNIOR, 2007, p.63). Essas tendências também se deram em Salvador.

No processo de introdução e fixação do futebol soteropolitano, falar da criação dos clubes é necessário, já que esse fato expressou

\footnotetext{
${ }^{9} \mathrm{Em}$ Salvador significa os jogos de futebol sem intuitos competitivos.

${ }^{10}$ Optamos por manter a ortografia de época nas citações de jornais.
}

Movimento, Porto Alegre, v. 17, n. 03, p. 79-95, jul/set de 2011. 
a forma com que se deu sua "caminhada" em Salvador. Os primeiros clubes não foram pensados para o futebol e sim para o críquete, esporte que havia chegado às terras baianas com os ingleses. Segundo Gama (1923, p. 319):

foram os membros da colonia ingleza na Bahia que fizeram a introducção de um jogo, cuja disputa, para elles, tinha já o cunho de Sport, - pois sendo a sua Pátria o berço do Sport moderno - tinham a noção exacta da significação do vocábulo. Esse jogo, foi o cricket, de origem genuinamente ingleza [...]. Esse cricket de então, era disputado no local hoje denominado Praça Duque de Caxias.

Como já visto, o primeiro clube de Salvador foi o Club de Cricket Victoria (1899), clube de jovens da elite local, que em 1901 passou a se chamar Sport Club Victoria, começando a praticar o futebol no ano seguinte. Seguindo a tendência apontada por Franco Júnior (2007), outros clubes foram criados em Salvador, clubes que podiam ainda ser de elite ou de origem popular ou ainda, ter base nas colônias estrangeiras. Nessa lista, vemos clubes como: Club Internacional de Cricket (novembro de 1899); Club de Natação e Regatas São Salvador (1902); Club de Regatas Itapagipe (1902); Sport Club Bahiano (1903); Sport Club São Paulo-Bahia (1903); Sport Club Santos Dumond (1904); Fluminense Foot-Ball Club; Sport Club Ypiranga (1906); Botafogo Sport Club (1914) e outros mais. Alguns tiveram vida curta, outros duraram tempo maior, mas da mesma forma foram extintos e poucos são os que existem até hoje, com alguns tendo sido criado em tempos mais recentes, como o Esporte Clube Bahia (1931).

Assim, em Salvador, vemos que os clubes fundados no primeiro momento, o da fase de "iniciação" do esporte, em sua maioria representavam a elite. Só mais adiante é que começamos a perceber a criação de clubes que também representavam a população de mais baixa renda, aquela mesma que era marginalizada nos clubes já existentes e mesmo era afastada das práticas formais de futebol, cabendo-lhes então jogar os seus "babas" nos espaços livres da cidade. 
Outra forma de analisar o futebol em Salvador é compreendendo como seus espaços de prática foram constituídos. Gama (1923) e Leal (2002) demonstram que o primeiro local de jogo foi uma praça conhecida como Campo da Pólvora, por essa permitir condições mínimas de jogo em relação aos padrões oficiais. Com o crescente interesse pelo futebol na cidade, não demorou muito para que fossem adaptados outros espaços, mais ajustados as exigências formais, surgindo aí bairro do Rio Vermelho.

[...] bairro afastado da cidade, aonde o melhor meio de se chegar eram os bondes e mesmo assim com dificuldades, o Rio Vermelho passou a ser cenário principal da prática de futebol em Salvador, quando então, "cuidou-se dos preparativos para que naquele arrabalde fosse realizados campeo-natos (sic) que antes, nos outros locais, ainda não eram realizados (LEAL, 2002, p. 182)".

No Rio Vermelho, o futebol era praticado nos mesmos espaços onde existiram as corridas de cavalo, ou seja, o futebol ainda não possuía um espaço especifico, denotando isso sua característica de esporte ainda em fase de organização na cidade de Salvador. Sobre esses espaços, Gama (1923, p. 320) nos mostra que:

[...] passou o ground, onde se disputavam os jogos, a ser no antigo prado do Rio Vermelho, onde o football teve os seus dias áureos com os encontros, dentre outros, entre o Sport Club Victoria (antigo Club de Cricket Victoria) e o Club de Regatas S. Salvador, os quaes naquelle tempo, eram os leaders do sport .

Sob essa condição ainda "primária", o futebol seguiu sendo no Rio Vermelho, até que veio "uma crise inevitável do foot-ball, crise esta que só pôde ser attribuída aos meios defficientes de conducção para o Rio Vermelho, que motivaram aos poucos, o empalidecimento da estrella do foot-ball" (GAMA, 1923, p. 320).

Também sobre o local dos jogos de futebol em Salvador, Leal (2002, p. 185) afirma que "a cidade se espalhava, havia necessidade 
de se construir um campo de foot-ball mais próximo do centro para satisfazer a todos os soteropolitanos, já que o esporte bretão tinha crescido acentuadamente e os bondes chegavam ao Rio Vermelho lotados".

Com isso, identificamos diferentes fases de ocupação dos espaços para a prática do futebol em Salvador. Uma primeira, quando o jogo se dava em praças (Campo da Pólvora e outras), onde ainda eram poucos os praticantes e seus jogos eram mais ligados ao aspecto da diversão daqueles que foram seus introdutores na cidade. Uma segunda se deu quando passou a ser necessário um espaço mais organizado, um espaço que permitisse uma prática mais sistematizada, com uma inicial organização de campeonatos, todavia, um espaço ainda adaptado, fazendo uso de outro já existente, no caso, os hipódromos, sendo essa a fase em que o futebol foi praticado no Rio Vermelho, tendo também voltado para o Campo da Pólvora.

A terceira fase foi aquela onde já se exigia um espaço específico, só do futebol, surgindo o Campo da Graça ${ }^{11}$, que foi construído especificamente para o futebol, o primeiro estádio em Salvador. Sua construção e inauguração permitiram uma nova realidade do futebol na cidade e

No dia 15 de novembro, na Graça, deu-se a grande festa do esporte bretão, não mais no ground, derby, prado ou hipódromo, e sim no campo construído naquele local, na esquina da Rua Catarina Paraguassu com a Avenida Euclides da Cunha e foi um dia de confraternização baiana. (LEAL, 2002, p. 186).

Se a construção do estádio satisfez uma necessidade, outra seria melhor organizar o futebol em Salvador, tendo se tornado imperioso a fundação de uma entidade que pudesse melhor sistematizá-lo. Uma primeira experiência se deu quando o Sport Club São Paulo-Bahia, ao lado de outros clubes, fundou a primeira Liga da Bahia (15 de novembro de 1904). Sobre isso, o Jornal de Notícias ${ }^{12}$ afirmou assim:

\footnotetext{
${ }^{11}$ Inaugurado em 15 de novembro de 1920 , no bairro da Graça, em Salvador.

${ }^{12}$ Jornal de Notícias de 17/11/1904.
}

Movimento, Porto Alegre, v. 17, n. 03, p. 79-95, jul/set de 2011. 
Ante-hotem, 15 às 11 horas do dia, reunidos alguns sócios dos clubes Vitória, Internacional, Bahiano e São Paulo, na sede deste, instalaram a LIGA BAHIANA DE SPORTS TERRESTRES que tem por fim dar maior desenvolvimento aos sports terrestres na Bahia.

Em setembro de 1913, outra liga foi criada, a Liga Brasileira de Sports Terrestres. Em Salvador, existiram ainda outras ligas futebolísticas, como: Liga Sportiva Nacional, a Liga Itapagipana e a Liga Rio Branco de Sports Terrestres.

A constituição dessas ligas correspondeu ao avançar da prática de futebol em Salvador. Dessa forma, organizar campeonatos, jogadores e espaços, era vital, já que esse esporte começava a alcançar outros praticantes, que não apenas os bons moços da "elite" soteropolitana. Ele já se alastrava pela cidade, chegando às várias camadas da população e aos vários bairros (mesmo que em campos improvisados $\left.{ }^{13}\right)$.

Além de aspectos como a introdução do futebol, a criação de clubes, a organização dos espaços de jogo, sua regulamentação e sua circulação por entre a população, alguns outros fatores significaram a maior capilarização do esporte na sociedade soteropolitana. Vemos, por exemplo, que a imprensa passou de notas soltas, para uma cobertura especifica, surgindo até uma associação de cronistas esportivos; os jogadores passaram a ser vistos com outros olhos pela população, tornando-se ídolos, participando de propagandas e sendo exaltados pela cidade; o futebol dialogava com outras práticas culturais, como o cinema, que passou a exibir jogos e ainda, a Bahia começava a querer dialogar esportivamente com o resto do país e a querer ver e ser vista pelos praticantes de futebol em outros estados e para isso, convidava clubes de fora do estado para jogarem amistosos, bem como participava de competições organizadas nacionalmente.

\footnotetext{
${ }^{13}$ Exemplo: Ground de Brotas, Largo Santos Dumont, Largo do Barbalho, Cabula, Engenho da Conceição, Largo da Rua do Oiro, Campo do Dique, Campo da Boa Viagem e outros.
} 
Analisando a trajetória percorrida pelo futebol em Salvador, vemos que ela não se deu de forma isolada e sim, articulada com projetos maiores da cidade e mesmo que se reconheça sua capacidade de autonomia em relação aos aspectos políticos e econômicos, é evidente que estes tiveram influência sobre o futebol.

Nesse sentido, deve-se dizer que entre fins do século XIX e início do século XX, no Brasil, em diferentes níveis e estágios, entrava em cena um projeto, o de modernização das cidades e o esporte e o futebol se ligavam a ele.

Melo (2001, p.14) nos mostra que toda a vivência desse processo de modernização, "[...] trouxe mudanças significativas para o cenário social e cultural brasileiro, principalmente a partir da segunda metade do século XIX. Nesse contexto, o esporte encontrou terreno fértil e possibilidades de se estabelecer no País...". Sobre essa relação entre modernidade e esporte, Rocha Junior (2009, p.1), afirma que essa se deu pelo fato do esporte "articular elementos como: maior exposição do corpo, movimento, risco e desafio, fatores que significavam uma busca pelo prazer e por uma excitação inovadora, se revestindo de elementos vividos e expressados pela modernidade".

Para melhor definir nossa análise acerca da modernidade, vemos que para Kumar (1996, p.473), esta

[...] extrai seu significado tanto do que nega como do que afirma. [...] a modernidade sente que o passado não tem lições para ela; seu impulso é constantemente em direção ao futuro. Ao contrário de outras sociedades, a sociedade moderna recebe bem e promove a novidade. É possível dizer que ela inventou a "tradição do novo".

Baudelaire (2007, p. 26), um intelectual que viveu a experiência francesa, tentando compreender a modernidade, seus conceito e sentidos, afirma que a "... modernidade é o transitório, o efêmero, o contingente...". Já Gunning (2004) ao trabalhar conceitualmente modernidade, nos fala que essa é mais uma mudança de experiência do que um período, formada por um conjunto diversificado de fatores. 
Também Salvador ${ }^{14}$ empreendeu ações que visaram remodelar seu espaço urbano, como: construção de avenidas, monumentos e edifícios e também a derrubada de outros espaços considerados inadequados a modernidade. Ainda, procurou-se adequar seus habitantes as novas exigências de comportamentos e posturas dessa modernidade, tentando levar para Salvador todo um propósito de instalar o novo e assim superar o declínio experimentado pela cidade. E foi a partir dessa fase e acompanhando as "reformas" da cidade, que o futebol ganhou maior peso em Salvador, tornando-se popular, com clubes constituídos, competições mais regulares e espaços próprios e de "[...] quanto ficou dito, ressalta claramente que a Bahia pôde festejar o seu grande feito de emancipação política, com os sports em pleno desenvolvimento e cultivo." E de mais a mais, "adoptados pela quase totalidade de sua população, os sports têm sido apoiados pelos poderes públicos da Bahia." (GAMA, 1923, p. $321)$.

\section{Breves Conclusões}

Numa análise final acerca do futebol em Salvador, podemos identificar que em sua trajetória, este se desenvolveu como uma prática cultural que ganhou às ruas da cidade, relacionando-se com outros elementos da cultura soteropolitana, se transformando no esporte de maior aceitação, até a atualidade.

O futebol em Salvador teve seu início como uma prática restrita a elite, uma atividade que representava a modernidade, que também foi um projeto da elite, e seus ganhos. A modernidade baiana tentou mudar a cidade em sua estrutura urbana, mas também a população em seus comportamentos e nesse sentido, o esporte e especificamente o futebol, foi um dos elementos utilizados para fazer acontecer e representar o ideário da modernidade, como um jogo de nobres e refinados hábitos ${ }^{15}$, distinguindo-se das práticas livres da população, que deveriam ser expurgadas da sociedade.

\footnotetext{
${ }^{14}$ Durante o governo estadual de J.J. SEABRA (1912-1916).

${ }^{15}$ Tratado como o conjunto de posturas e comportamentos no trato social.
} 
Entendendo que uma prática cultural não é estática e que ganha sentidos diversos a partir do que se opera em cada realidade, num diálogo com o que é peculiar a cada local, é que percebemos que o futebol em Salvador foi modificando-se, num processo que não foi linear e nem uniforme. $\mathrm{O}$ futebol tornou-se uma atividade de caráter popular, ganhando espaço como um esporte que não era apenas a representação do modo europeu de ser, mas sim, demonstrava a forma da população baiana de lidar com o que até então era uma novidade, enfrentando as oposições e resistências da elite.

Assim é que o futebol foi apropriado e reorganizado pela massa população soteropolitana, incorporando formas espontâneas e diversificadas de jogar e ver o jogo, constituindo clubes e ligas, diferentes das inicialmente existentes. Da mesma forma, essa população se apropriou da cidade, espalhando por Salvador campos de jogo, atendendo seus interesses em acessar o futebol, mesmo que de uma forma que não fosse à padronizada. Assim, ao se apoderar do futebol, a população local também buscou se apossar dos adventos da modernidade, representando isso à forma com que na Bahia se deu o processo de entrada e incorporação do futebol, como uma prática cultural da modernidade. 
Soccer in Salvador: the beginning of a history (1899-1920)

Abstract: This study accosts the football in Salvador$\mathrm{BA}$ and it aims to identify ways and meanings of its arrival in the city and examine its history and construction as a social practice, between 1899 and 1920. This text is justified by the importance of Salvador in politics and economy of the country, as it was one of the first cities to have football. The football began in the elite, as a practice of "modern" values to increase in popularity, reaching every city, in the same way the clubs were formed, the elite at the beginning, after popular foreigner's colony. The practice began in squares, only later, was built its own field, its trajectory follows the process of trying to include the city in modernity.

Keywords: Soccer. History. Salvador-BA.Modernity.

Fútbol en Salvador: el comienzo de una historia (1899-1920)

Resumen: Este estudio aborda el fútbol en SalvadorBA y tiene como objetivo identificar las formas y significados de su llegada a la ciudad, estudiar su historia y de la construcción como una práctica social, entre 1899 y 1920. Este texto se justifica por la importancia de Salvador en la política y en la economía, siendo una de las primeras ciudades que tienen fútbol. El fútbol comenzó en la elite, como una práctica de valores "modernos", hasta ganar popularidad por ir a toda la ciudad y de manera similar constituidos clubes, primero de elite y después populares o de colonias extrajeras. La práctica se inició en los parques, para construir un campo propio y su trayectoria sigue el proceso de tratar de incluir la ciudad en la modernidad. Palabras clave: Fútbol, Historia. Salvador-BA. Modernidad 


\section{REFERÊNCIAS:}

BAUDELAIRE, C. Sobre a modernidade. 6.ed. São Paulo: Paz e Terra, 2007.

BYINGTON, C. A riqueza simbólica do futebol. Revista Psicologia atual. São Paulo, v.5, n.25, p.20-32, 1982.

BURKE, P. O que é história cultural? Rio de Janeiro: Jorge Zahar, 2005.

DAMATTA, R. (org.) Universo do Futebol: esporte e sociedade brasileira. Rio de Janeiro: Pinakotheke, 1982.

A bola corre mais que os homens. Rio de Janeiro: Rocco, 2006.

FOER, F. Como o futebol explica o mundo: um olhar inesperado sobre a globalização. Rio de Janeiro: Jorge Zahar, 2005.

FRANCO JUNIOR, Hilário. A dança dos deuses: futebol, sociedade e cultura. São Paulo: Companhia das Letras, 2007.

GAMA, M. Como os "sports" se iniciaram e progrediram na Bahia. Diário oficial do Estado da Bahia, Edição Especial do Centenário. Salvador: s.e, 1923.

GIULIANOTTI, R. Sociologia do futebol: dimensões históricas e socioculturais do esporte das multidões. São Paulo: Nova Alexandria, 2002.

GUEDES, Simoni L. Futebol e identidade nacional: reflexões sobre o Brasil. In: PRIORE, Mary Del e MELO, Victor Andrade de (Org). História do esporte no Brasil: do império aos dias atuais. São Paulo: UNESP, 2009.

GUNNING, Tom. O retrato do corpo humano: a fotografia, os detetives e os primórdios do cinema. In: CHARNEY, Leo, SCHWARTZ, Vanessa R. (orgs.). 0 cinema e a invenção da vida moderna. 2. ed. São Paulo: Cosac \& Naify, 2004.

HALL, Stuart. A identidade cultural na pós-modernidade. 10. ed. Rio de Janeiro: DP\&A, 2005.

KUMAR, Krishan. Verbete Modernidade. In: OUTHWAITE, William; BOTTOMORE, Tom. Dicionário do pensamento social do século XX. Rio de Janeiro: Jorge Zahar, 1996.

LEAL, Geraldo da Costa. Perfis urbanos da Bahia: os bondes, a demolição da Sé, o futebol e os gallegos. Salvador: Gráfica Santa Helena, 2002.

LEITE, Rinaldo C. N., ROCHA JUNIOR, Coriolano P. e SANTOS, Henrique Sena dos. Esporte, cidade e modernidade: Salvador. In: MELO, Victor Andrade de (org). Os sports e as cidades brasileiras: transição dos séculos XIX e XX. Rio de Janeiro: Apicuri, 2010b. 
MELO, Victor Andrade de. Futebol: que história é essa?! In: CARRANO, Paulo Cesar R. Futebol: paixão e política. Rio de Janeiro: DP\&A, 2000.

CidadeSportiva: primórdios do esporte no Rio de Janeiro. Rio de Janeiro: Relume-Dumará: FAPERJ, 2001.

Dicionário do esporte no Brasil: do século XIX ao início do século XX. Campinas - São Paulo: Autores Associados; Decania do CCS-UFRJ, 2007a.

. (Org.). História comparada do esporte. Rio de Janeiro: Shape, 2007b.

PEREIRA, L. A. de M. Footballmania: uma história social do futebol no Rio de Janeiro, 1902-1935. Rio de Janeiro: Nova Fronteira, 2000.

ROCHA JUNIOR, Coriolano P. da. Primórdios do esporte na cidade de Salvador. In: CONGRESSO BRASILEIRO DE CIÊNCIAS DO ESPORTE, 16. CONGRESSO INTERNACIONAL DE CIÊNCIAS DO ESPORTE, 3., 2009, Salvador. Anais... Disponível em: <http://cbce.tempsite.ws/congressos/index.php/CONBRACE/XVI/paper/view/ 663/847>Acesso em: 01 out. 2009.

SALVADOR, Marco A. Santoro. A memória da copa de 1970: esquecimentos e lembranças do futebol na construção da identidade nacional. Tese de Doutorado. Rio de Janeiro: PPGEF-UGF, 2005.

Endereço para correspondência:

Coriolano Pereira da Rocha Junior

Rua Alagoinhas - 489/504a

Cond. Mirante do Vale

Rio Vermelho

Salvador - Bahia

CEP.41.940-620

Recebido em: 09-12-2010

Aprovado em: 21-07-2011 
